\title{
Estimating the Continental Response to Global Warming Using Pattern-Scaled Sea Surface Temperatures and Sea Ice ${ }^{\mathscr{O}}$
}

\author{
ADELINE BICHET \\ CNRS-LGGE/MEOM, Grenoble, France \\ Paul J. Kushner AND LAWRENCE MudryK \\ Department of Physics, University of Toronto, Toronto, Ontario, Canada
}

(Manuscript received 25 January 2016, in final form 6 July 2016)

\begin{abstract}
Better constraining the continental climate response to anthropogenic forcing is essential to improve climate projections. In this study, pattern scaling is used to extract, from observations, the patterned response of sea surface temperature (SST) and sea ice concentration (SICE) to anthropogenically dominated long-term global warming. The SST response pattern includes a warming of the tropical Indian Ocean, the high northern latitudes, and the western boundary currents. The SICE pattern shows seasonal variations of the main locations of sea ice loss. These SST-SICE response patterns are used to drive an ensemble of an atmospheric general circulation model, the National Center for Atmospheric Research (NCAR) Community Atmosphere Model, version 5 (CAM5), over the period 1980-2010 along with a standard AMIP ensemble using observed SST-SICE. The simulations enable attribution of a variety of observed trends of continental climate to global warming. On the one hand, the warming trends observed in all seasons across the entire Northern Hemisphere extratropics result from global warming, as does the snow loss observed over the northern midlatitudes and northwestern Eurasia. On the other hand, 19802010 precipitation trends observed in winter over North America and in summer over Africa result from the recent decreasing phase of the Pacific decadal oscillation and the recent increasing phase of the Atlantic multidecadal oscillation, respectively, which are not part of the global warming signal. The method holds promise for near-term decadal climate prediction but as currently framed cannot distinguish regional signals associated with oceanic internal variability from aerosol forcing and other sources of short-term forcing.
\end{abstract}

\section{Introduction}

It is known that imposing observed sea surface temperature (SST) and sea ice concentration (SICE) in an atmospheric general circulation model (AGCM) - the so-called AMIP methodology-determines much of that model's circulation and land surface temperature variability, even in the absence of additional radiative forcing (e.g., Gates 1992; Lau 1997; Hoerling et al. 2008; Deser and Phillips 2009; Compo and Sardeshmukh 2009; Bichet et al. 2011). For example, coupled ocean-atmosphere general circulation

Supplemental information related to this paper is available at the Journals Online website: http://dx.doi.org/10.1175/ JCLI-D-16-0032.s1.

Corresponding author address: Adeline Bichet, CNRS-LGGE/ MEOM, 38041 Grenoble, France.

E-mail: adeline.bichet@lgge.obs.ujf-grenoble.fr models (AOGCMs) have difficulty reproducing observed multidecadal continental climate trends in part because they have difficulty capturing observed SST trends on these time scales (e.g., Shin and Sardeshmukh 2011). The strong control of continental climate by variations in SST operates via atmospheric advection (e.g., Compo and Sardeshmukh 2009) and via driving of atmospheric teleconnections. Precipitation variations in North America have been linked to multidecadal variability in SSTs associated with the Atlantic multidecadal oscillation (AMO) and the Pacific decadal oscillation (PDO; e.g., McCabe et al. 2004; Schubert et al. 2004; Seager et al. 2005; Wang et al. 2009; Dai 2013). In addition, much of the Sahel drying observed in the second half of the twentieth century results from variations in the North Atlantic and Indian Ocean SSTs (e.g., Giannini et al. 2003; Hoerling et al. 2006; Zhang and Delworth 2006; Ting et al. 2009). In the tropics, El Niño-Southern Oscillation (ENSO) is also known to cause tropical droughts and floods on interannual time scales, and SST variations in 
other tropical basins have previously been linked to dramatic climate variations in various regions including $\mathrm{Eu}-$ rope (e.g., Fletcher and Kushner 2013; Bichet et al. 2014). More recently, interest has grown in the role of sea ice variations and trends in controlling lower-latitude climate (e.g., Screen and Simmonds 2010; Deser et al. 2015).

Ocean surface variability (including variations in sea ice) arises from a variety of sources:

1) internal climate variability;

2) variability on the global scale driven by long-term radiative forcing from well-mixed greenhouse gases and from the global-mean impact of natural and anthropogenic forcing-as described below, we will assume that long-term radiative forcing is dominated by the effect of global warming (GW) from greenhouse gases;

3) regional variability driven by short-term forcings such as aerosols and ozone-depleting substances; and

4) coupled and nonlinear variability such as feedbackdriven amplification, non-additive responses to the different sources of variability listed above, and driving originating from land-atmosphere-ocean coupling.

While most of these effects are challenging to predict, model, and estimate empirically, previous literature suggests that the GW signal is relatively strong and can potentially be estimated from observations and climate simulations (e.g., Santer et al. 1990; Hoerling et al. 2011; Mohino et al. 2011; Tebaldi and Arblaster 2014). In this study, we estimate the patterned GW component of ocean surface variability (including sea ice variability) from observations, using a simple statistical method based on pattern scaling (Santer et al. 1990; Tebaldi and Arblaster 2014). By construction, the resulting pattern represents a multidecadal variation coherent with the low-frequency component of global-mean SSTs. We then use this GW pattern to drive an AGCM and analyze its continental climate response, as a complement to the classical AMIP approach.

This approach was originally proposed as a method of decadal prediction of the forced continental response to climate change. Hoerling et al. (2011) used this method to predict the forced component of the decadal mean (201120) changes in temperature and precipitation over North America. Bichet et al. (2015) evaluated several aspects of the method, ${ }^{1}$ using a perfect model testing framework

\footnotetext{
${ }^{1}$ Bichet et al.'s (2015) terminology was different from that used here, although the methodology is very similar. In particular, what we here call the GW component of the climate response was called the "anthropogenically forced" component in Bichet et al. (2015). We made this change to more clearly distinguish the GW response from the response to short-term forcings from anthropogenic aerosols and other sources.
}

that is described below, and showed that the estimation method captures a significant fraction of the forced SST trend pattern. The current study aims to improve on the method of Bichet et al. (2015) and apply this approach by using it to survey regional aspects of climatic trends over the past three decades. We illustrate the potential of the method for quantitative attribution of regional climate trends to forced SST trends, which sets the stage for using the method to carry out decadal prediction on regional scales.

After describing the observational datasets (section 2a) and the AMIP and other simulations used (section 2b), we update the method of Hoerling et al. (2011) and Bichet et al. (2015) to derive a time-varying estimate of the SST and SICE response to GW (section 2c). While in Bichet et al. (2015) this estimate was purely observationally based, here we bring in some information from climate models on the time dependence of GW. We then compare the SST-SICE pattern associated with GW (called $S_{\mathrm{GW}}$ ) with recent observed variability ( $S_{\text {Obs }}$; section 2 d) over the 1980-2010 period. Focusing on regions and seasons where the AMIP simulations forced with $S_{\text {Obs }}$ reproduce reliably the observed trends, we then use the ensemble forced with $S_{\mathrm{GW}}$ to attribute various aspects of the observed trends to $\mathrm{GW}$ as opposed to other drivers such as internal climate variability. We first focus on the thermal response of the Northern Hemisphere in all seasons (section 3a) before investigating the hydroclimate response in the three following examples: winter snow cover at high northern latitudes (section $3 \mathrm{~b}$ ), winter precipitation in North America (section 3c), and summer precipitation in Africa (section 3d). We conclude with a brief discussion of extensions of the method (section 4).

\section{Method and dataset}

\section{a. Observational datasets}

Monthly global SST and SICE are derived from the National Center for Atmospheric Research (NCAR) observational product (Hurrell et al. 2008, hereafter Hurrell; available for download at https:// climatedataguide.ucar.edu/climate-data/merged-hadleynoaaoi-sea-surface-temperature-sea-ice-concentrationhurrell-et-al-2008), which is a merged product based on version 1 of the Hadley Centre Sea Ice and SST dataset (HadISST1) and version 2 of the National Oceanic and Atmospheric Administration (NOAA) weekly optimal interpolation SST. It covers the time period from 1870 to 2012 on a one-degree grid. It is the standard driving dataset used in the NCAR AGCM simulations, and its SST twentieth-century trend map agrees well with the twentieth-century trend map that is 
obtained with all the observational SST datasets tested in Solomon and Newman (2012) after statistical correction accounting for sampling of ENSO variability.

Land surface temperature is from version 4 of the Climatic Research Unit (CRU) of the University of East Anglia monthly, 1850-present, global land surface temperature anomalies product (CRUTEM4; Jones et al. 2012). Precipitation is from version 3.21 of the CRU monthly, 1901-2012 gridded precipitation product (CRU TS3.21; Harris et al. 2014), which has global coverage excluding Antarctica. Because of relatively large uncertainties in observation-based estimates of gridded Northern Hemisphere snow water equivalent (SWE), we examine two such datasets, each covering the 1981-2010 period at daily frequency. The first is the National Aeronautics and Space Administration (NASA) MERRA reanalysis (Rienecker et al. 2011). The second is the GlobSnow product (Takala et al. 2011; http://www. globsnow.info/), which is based on combined information from satellite passive-microwave observations and local weather station data. Note that GlobSnow does not report values in regions of complex topography (i.e., alpine regions). MERRA SWE has been shown to correlate well with other reanalysis-based SWE products, and GlobSnow serves as a more empirically based product, which still has reasonable agreement with other analyses (Mudryk et al. 2015). We derive snow cover fraction (SCF) for each dataset from the daily values of SWE, setting SCF to 1 when daily SWE is higher than $4 \mathrm{~mm}$ and to 0 otherwise. The monthly SCF calculated in this manner represents the fraction of the month when each grid cell is snow covered.

\section{b. Models and experiments}

As in Bichet et al. (2015), we evaluate the patternscaling method used to derive $S_{\mathrm{GW}}$ in a perfect model framework based on the NCAR Community Earth System Model, version 1 (CESM1; version 1.1.1alpha01g), large initial condition ensemble (Kay et al. 2015). CESM1 includes the Community Atmosphere Model, version 5 (CAM5; nominally $1^{\circ}$ finite-volume grid, tag f09), the Community Land Model, version 4 (CLM4), the Community Ice Code, version 4 (CICE4), and the Parallel Ocean Program, version 2 (POP2; nominally one-degree Greenland dipole grid, tag g16). We evaluate 35 realizations covering the time period 1920-2012. Each realization is forced with identical time-dependent prescriptions for well-mixed greenhouse gases, ozone, aerosols, volcanic emissions, and solar variability consistent with the protocol from phase 5 of the Coupled Model Intercomparison Project (CMIP5; Taylor et al. 2012). These prescriptions are the standard datasets provided by NCAR. They represent estimates of historical values up until 2005 and follow the $8.5 \mathrm{~W} \mathrm{~m}^{-2}$ representative concentration pathway from 2006 to 2012 . Initially, 35 members were produced at NCAR; since the publication of Bichet et al. (2015), 5 more members were produced at the University of Toronto using Compute Canada's SciNet facility.

The AGCM that we use contains the same atmosphereland components as the coupled model described above but at coarser resolution (CAM5/CLM4 version 1.0.4, nominally $2^{\circ}$ grid, tag f19). The same radiative forcing is prescribed in the AGCM as in the coupled model. SST and SICE are prescribed in two different ways as described in section 2d; we perform two 10-member ensembles (one with each scenario described in section $2 d$ ) covering the time period 1980-2010 and forced with identical atmospheric radiative forcings as the CESM1 integrations. All AGCM realizations are derived from a January 1975 climate state taken from a "parent run" starting in 1970.

We derive the GW temporal signal $g(t)$, described in the next subsection from CMIP5 SSTs for the period 1900-2040 (26 models, with one historical realization per model; see Table 1) driven with the same radiative forcing prescription as the CESM1 historical integrations (Taylor et al. 2012). This represents a departure from Bichet et al. (2015), in which, following the method of Hoerling et al. (2011), we derived the GW temporal signal $g(t)$ from 1900-2008 observed SSTs. As compared to Bichet et al. (2015), this choice leads to a less linear evolution of $g(t)$ in the historical period (cf. solid and dashed red curves in Fig. 1) owing to the accelerated increase of CMIP5 SSTs between 2012 and 2040. The advantage of this approach is that it allows us to consistently extend the framework to support work in progress on decadal prediction of the forced component of climate variability. As in Bichet et al. (2015), the spatial pattern of the GW is still derived from observations.

\section{c. Generating $S_{\mathrm{GW}}$ : Method updates from Bichet et al. (2015)}

The time-varying estimate of the SST and SICE response to GW that is used to force the model is called $S_{\mathrm{GW}}$. It is developed using the Bichet et al. (2015) pattern-scaling method, which is updated here with slightly different notation and terminology. ${ }^{2}$ As in Bichet et al. (2015), we generate $S_{\mathrm{GW}}$ using the classical

\footnotetext{
${ }^{2}$ Bichet et al.'s (2015) terminology was different from that used here, although the methodology is very similar. In particular, what we here call the GW component of the climate response was called the "anthropogenically forced" component in Bichet et al. (2015). We made this change to more clearly distinguish the GW response from the response to short-term forcings from anthropogenic aerosols and other sources.
} 
TABLE 1. The 26 CMIP5 models used in this study, distinguishing the models including some representation of the indirect aerosol effect. (Expansions of acronyms are available online at http://www.ametsoc.org/PubsAcronymList.)

\begin{tabular}{|c|c|c|}
\hline Modeling center & Model & $\begin{array}{l}\text { Indirect aerosol effect included: using aerosol } \\
\text { emissions instead of aerosol optical depth }\end{array}$ \\
\hline \multirow[t]{2}{*}{ CSIRO-BoM } & ACCESS1.3 & Yes \\
\hline & ACCESS1.0 & Yes \\
\hline CCCma & CanESM2 & Yes \\
\hline CNRM-CERFACS & CNRM-CM5 & Yes \\
\hline CSIRO-QCCCE & CSIRO Mk3.6.0 & Yes \\
\hline \multirow[t]{2}{*}{ NASA GISS } & GISS-E2-H & Yes \\
\hline & GISS-E2-R & Yes \\
\hline \multirow{2}{*}{$\begin{array}{l}\text { Met Office Hadley Centre [MOHC; additional realizations } \\
\text { by the National Institute for Space Research (INPE)] }\end{array}$} & HadGEM2-ES & Yes \\
\hline & HadGEM2-CC & Yes \\
\hline \multirow[t]{3}{*}{ IPSL } & IPSL-CM5A-LR & Yes \\
\hline & IPSL-CM5A-MR & Yes \\
\hline & IPSL-CM5B-LR & Yes \\
\hline MRI & MRI-CGCM3 & Yes \\
\hline \multirow[t]{2}{*}{ Norwegian Climate Centre (NCC) } & NorESM1-M & Yes \\
\hline & NorESM1-ME & Yes \\
\hline INM & INM-CM4.0 & Yes \\
\hline MIROC & MIROC5 & Yes \\
\hline \multirow[t]{2}{*}{ NSF-DOE-NCAR } & CESM1(CAM5) & Yes \\
\hline & CESM1(BGC) & No \\
\hline \multirow[t]{2}{*}{$\mathrm{BCC}$} & BCC_CSM1.1 & No \\
\hline & BCC_CSM1.1(m) & No \\
\hline NCAR & CCSM4 4 & No \\
\hline \multirow[t]{2}{*}{ Max Planck Institute for Meterology (MPI-M) } & MPI-ESM-LR & No \\
\hline & MPI-ESM-MR & No \\
\hline $\mathrm{CMCC}$ & CMCC-CMS & No \\
\hline FIO & FIO-ESM & No \\
\hline
\end{tabular}

pattern-scaling method (e.g., Santer et al. 1990; Tebaldi and Arblaster 2014), which consists of multiplying a time-invariant spatial pattern by a temporal pattern. Here, the temporal pattern $g(t)$ is understood to represent the timing of GW. It is derived over the time period 1900-2040 from the CMIP5 multimodel mean globalmean, annual-mean SSTs, smoothed using a cubic spline function [see Bichet et al. (2015) and solid curves in Fig. 1]. The time-invariant spatial pattern $h(\mathbf{x})$ represents the spatial pattern of the SST-SICE response to GW. It is obtained by linearly regressing Hurrell SSTSICE on $g(t)$ separately for each calendar month over the time period 1900-2012. The full, time-varying $S_{\mathrm{GW}}$ data are obtained for the time period 1900-2040 by multiplying $g(t)$ with $h(\mathbf{x})$ [i.e., forming the product $g(t) h(\mathbf{x})$ ] before adding the climatological mean Hurrell SSTSICE. In this study, we only use $S_{\mathrm{GW}}$ over the period 1980-2010, and in future work we will consider the time period up to 2040. As illustrated in Fig. 1, the temporal pattern $g(t)$ consists of a slowly varying rate of anthropogenic greenhouse warming, modulated by effects such as aerosol forcing and internal variability. The method assumes that the pattern of the SST-SICE response to GW is time invariant and linearly coherent with $g(t)$. Hence, $S_{\mathrm{GW}}$ represents neither the response to regional-scale short-term forcings nor the anthropogenic impact on oceanic internal variability.

By testing the method with the CESM1 large initial condition ensemble, Bichet et al. (2015) estimate that about $56 \%$ of the spatial variability of the $h(\mathbf{x})$ pattern in SST can be captured by this approach, with the remainder attributed to other sources of SST-SICE variability along the lines described in the introduction. In this section, we test the four following method updates to improve this estimate. Using the same CESM1 evaluation framework as in Bichet et al. (2015) we 1) lengthen the period of estimation of $g(t)$ from 1900-2008 of Bichet et al. (2015) to $1900-2012,2$ ) better account for seasonality by obtaining separate patterns of $h(\mathbf{x})$ for each calendar month [instead of directly computing $h(\mathbf{x})$ from annual-mean SSTs as in Bichet et al. (2015)], 3) avoid setting nonstatistically significant values of $h(\mathbf{x})$ in $S_{\mathrm{GW}}$ to zero to generate more physically representative patterns (unlike in Bichet et al. 2015), and 4) simplify the method by not applying the temporal filtering of data prior to regression [high-pass filtering in Bichet et al. (2015)].

As in Bichet et al. (2015), we evaluate the impact of these changes by applying the method to the CESM1 large initial condition ensemble described in section $2 b$. We treat the large ensemble as representative of observed 


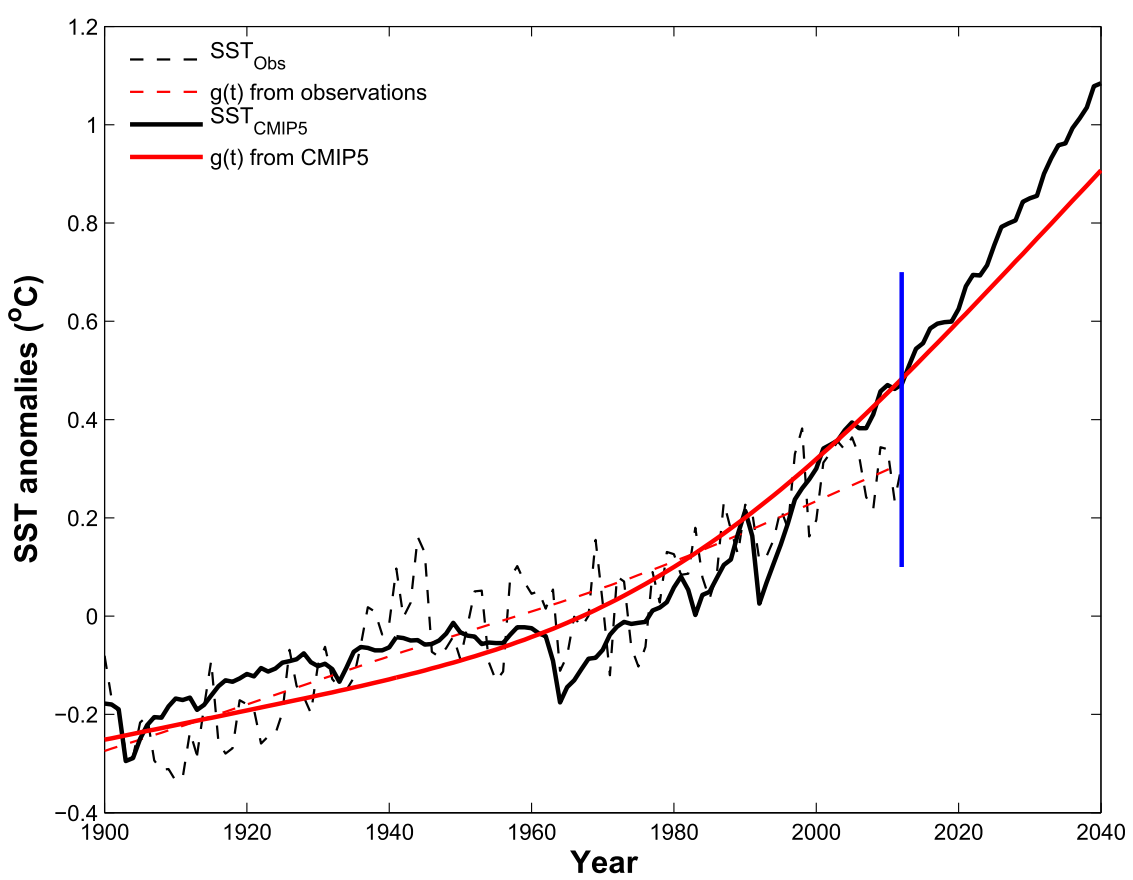

FIG. 1. Annual-mean, global-mean SST anomalies $\left({ }^{\circ} \mathrm{C}\right.$, black curves) and associated $g(t)$ (red curve) taken from Hurrell over 1900-2008 (dashed curves, identical to Bichet et al. 2015) and from the CMIP5 multimodel mean over 1900-2040 (solid curve). Anomalies are with respect to the mean of the common period (1900-2008). The vertical blue line represents the cutoff for the analysis period.

variability and test whether a forced pattern $h(\mathbf{x})$ can be captured from our statistical approach. Figure $2 \mathrm{a}$ shows the spatial correlation between global SSTs $h(\mathbf{x})$ computed from each of the 30 members of the CESM1 large ensemble and global SSTs $h(\mathbf{x})$ computed from the ensemble mean, excluding each time the ensemble member being tested. The averaged correlation in Fig. $2 \mathrm{a}(1)$ is about 0.75 , indicating that in the CESM1 large ensemble, over $1920-2005$, on average $56 \%$ of the spatial variance of the computed $h(\mathbf{x})$ is coherent with the spatial variance of the ensemble mean $h(\mathbf{x})$. We interpret this as meaning a single (pseudo) observation captures about half of the model's forced long-term signal. The averaged correlation increases to 0.80 (64\%) when the time period is increased [Fig. 2a(2)] and further to $0.85(72 \%)$ when nonsignificant values are not set to 0 [Fig. 2a(3)]. Not applying the time filtering of Bichet et al. (2015) has little effect [Fig. 2a(4)], and the annualmean results are also not sensitive to first breaking down the $h(\mathbf{x})$ estimate into monthly means [Fig. 2a(5)]. Therefore, we conclude that the three changes improve the original method by removing more of the non-GW signal from $h(\mathbf{x})$, improving its overall spatial distribution, and accounting for seasonal changes. As an additional check, the previous tests used the original 30 members of the large ensemble from Bichet et al. (2015). Using 35 instead of 30 members also has very little effect on the tests [Fig. 2a(6)]. As shown in Fig. 2b, the centered rootmean-square error of $h(\mathbf{x})$ decreases by a total of about 0.2 with the method updates discussed above.

Similarly, Fig. 3a shows a seasonal breakdown of the spatial correlation between Northern Hemisphere SICE $h(\mathbf{x})$ computed from each of the 35 members of the CESM1 large ensemble and Northern Hemisphere SICE $h(\mathbf{x})$ computed from the ensemble mean, excluding each time the ensemble member being tested. According to Figs. 3a(1)-(4), the averaged correlation is about 0.85 for the January-March (JFM) mean, 0.83 for the April-June (AMJ) mean, 0.93 for the July-September (JAS) mean, and 0.96 for the October-December (OND) mean, with a larger range of correlation coefficients for JFM and AMJ than for JAS and OND. This indicates that in the CESM1 large ensemble, over $1920-2012$, on average $72 \%, 69 \%, 87 \%$, and $92 \%$ of the spatial variance of the computed $h(\mathbf{x})$ is coherent with the spatial variance of the ensemble mean $h(\mathbf{x})$, for JFM, AMJ, JAS, and OND, respectively. According to Fig. 3b(1)-(4), the centered root-mean-square error of $h(\mathbf{x})$ is about 0.8 for JFM and AMJ and 0.45 for JAS and OND. Therefore, we conclude that for SICE, the method removes more of the non-GW signal from $h(\mathbf{x})$ and produces a more consistent spatial distribution of 

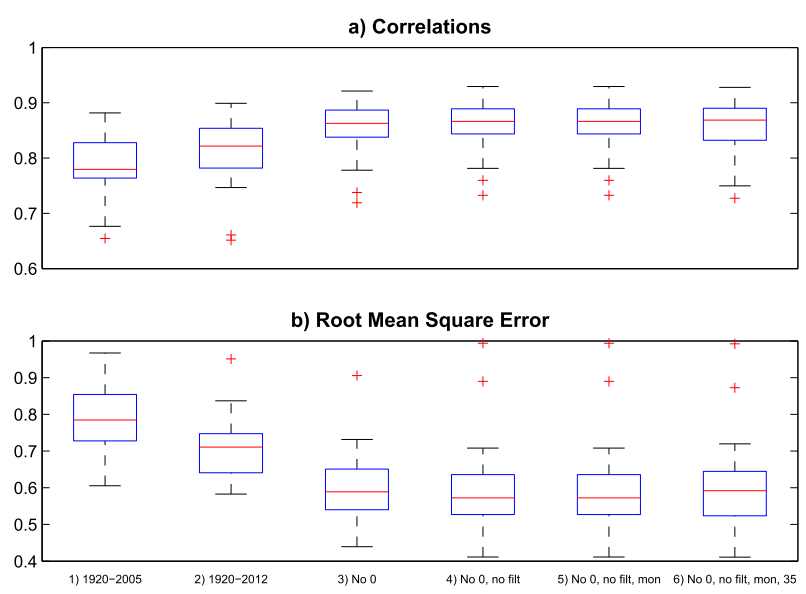

FIG. 2. (a) Centered spatial correlation coefficient between $h(\mathbf{x})$ computed from 30 members of the CESM1 large ensemble and $h(\mathbf{x})$ computed from the ensemble mean excluding the ensemble member being tested. Referring to the numbers along the $x$ axis: $1)$ the $h(\mathbf{x})$ is computed for annual-mean, global SSTs over 19202005 (identical to Fig. 4b from Bichet et al. 2015); 2) as in 1), but $h(\mathbf{x})$ is computed over 1920-2012;3) As in 2), but nonsignificant $h(\mathbf{x})$ values are not set to $0(\mathrm{No} 0) ; 4)$ as in 3 ), but no filtering is applied prior to regression (No 0, no filt); 5) as in 4), but $h(\mathbf{x})$ is obtained separately for each calendar month prior annual averaging (No 0 , no filt, mon); and 6) as in 5), but using 35 ensemble members ( 0 , no filt, mon, 35). (b) As in (a), but for the centered root-meansquare error.

$h(\mathbf{x})$ in summer and fall than in winter and spring, which is expected owing to the large internal variability of SICE during winter.

\section{d. SST and SICE forcing datasets for AGCM simulations}

In section 3, we will compare an ensemble of CAM5 AGCM simulations forced with observed SST-SICE (referred to as AMIP) to an ensemble forced with $S_{\mathrm{GW}}$ (referred to as GW) derived from pattern scaling in SST and SICE. We first compare the AMIP and GW SSTSICE driving fields to each other by calculating simple linear trend maps. Figure 4 shows the annual-mean SST linear trends $\left({ }^{\circ} \mathrm{C}\right.$ decade $^{-1}$ over $\left.1980-2010\right)$ taken from $S_{\text {Obs }}$ (Fig. 4a, showing trends for the Hurrell SST used for the AMIP ensemble), $S_{\mathrm{GW}}$ (Fig. 4b, used for the GW ensemble; this map represents $h(\mathbf{x})$ times the linear trend in $g(t)$ over the 1980-2010 period), and the trend in $S_{\text {Obs }}$ minus the trend in $S_{\mathrm{GW}}$ (Fig. 4c). There are few appreciable changes in the pattern across the season in SST trends. Similarly, Fig. 5 shows a seasonal breakdown of the SICE trends (\% decade ${ }^{-1}$ over 1980-2010) for the SICE used in the AMIP and GW ensembles. While Figs. 4a and 5a illustrate recent observed variability in SST and SICE, Figs. 4b and 5b represent the regional structure of the pattern of warming and sea ice loss associated, according to this estimation method, with long-term global warming. Observed AMIP SSTs (Fig. 4a) show a warming trend over the high northern latitudes $\left(+0.6^{\circ} \mathrm{C}_{\text {decade }}{ }^{-1}\right.$ on average in the Greenland Sea and the North Sea), the western Pacific Ocean $\left(+0.3^{\circ} \mathrm{Cdecade}^{-1}\right.$ on average $)$, and the tropical Indian Ocean $\left(+0.2^{\circ} \mathrm{Cdecade}^{-1}\right.$ on average $)$ and a cooling trend over the eastern Pacific Ocean and the Southern Ocean $\left(-0.2^{\circ} \mathrm{Cdecade}^{-1}\right.$ on average $)$. In the Atlantic and Pacific Oceans, the observed trends show a pattern that resembles the negative phase of the PDO and the positive phase of the AMO, respectively. In agreement with Bichet et al. (2015) and previous studies (e.g., Lu et al. 2008; Ting et al. 2009; Xie et al. 2010; Mohino et al. 2011; Wu et al. 2012), our estimated SST response to global warming (Fig. 4b) shows an average warming of $+0.2^{\circ} \mathrm{Cdecade}^{-1}$ in the tropical Indian Ocean, the South Atlantic Ocean, the southern Indian Ocean $\left(60^{\circ}-45^{\circ} \mathrm{S}, 60^{\circ} \mathrm{W}-120^{\circ} \mathrm{E}\right)$, the northern North Pacific Ocean, the Arctic Ocean and subarctic ocean, and the northern and southern midlatitudinal coasts (including the western boundary currents). The maps in Fig, 4 display no evident pattern related to known modes of oceanic internal variability (in these regions, SST trends from $S_{\mathrm{GW}}$ are smaller in magnitude than $0.1^{\circ} \mathrm{Cdecade}^{-1}$ ). Globally, the observed trends $\left(+0.98^{\circ} \mathrm{Cdecade}^{-1}\right)$ are somewhat warmer than the GW trends $\left(+0.85^{\circ} \mathrm{Cdecade}^{-1}\right)$ by about $+0.15^{\circ} \mathrm{Cdecade}^{-1}$ and show a larger interhemispheric difference $\left(+0.62^{\circ} \mathrm{C}\right.$ decade $^{-1}$ over the Northern Hemisphere and $-0.42^{\circ} \mathrm{Cdecade}^{-1}$ over the Southern Hemisphere). These differences (Fig. 4c) illustrate the role of oceanic internal variability and/or that part of the anthropogenic response that does not scale simply with anthropogenic global warming, in modulating the SST response to global warming between 1980 and 2010. In particular, the dominant signal is warming of the Northern Hemisphere (mostly due to North Atlantic and North Pacific warming) and an overall cooling of the Southern Hemisphere (mostly due to Southern Ocean cooling).

Regarding sea ice, the Hurrell dataset shows for 1980-2010 a summer and autumn sea ice loss over the Beaufort Sea, Chukchi Sea, Laptev Sea, and Baffin Bay and a winter and spring sea ice loss over the Okhotsk, Labrador, and Laptev Seas (Fig. 5a). In agreement with previous studies (e.g., Park et al. 2015), our estimated SICE response to global warming (Fig. 5b) shows a similar pattern to the observations in summer but not in autumn (no sea ice loss over the Chukchi and Beaufort Seas) or in winter and spring (sea ice growth over the Okhotsk Sea). We conclude that most of the summer and autumn sea ice loss observed at high northern latitudes is coherent with the long-term GW signal but that 
a) Correlations

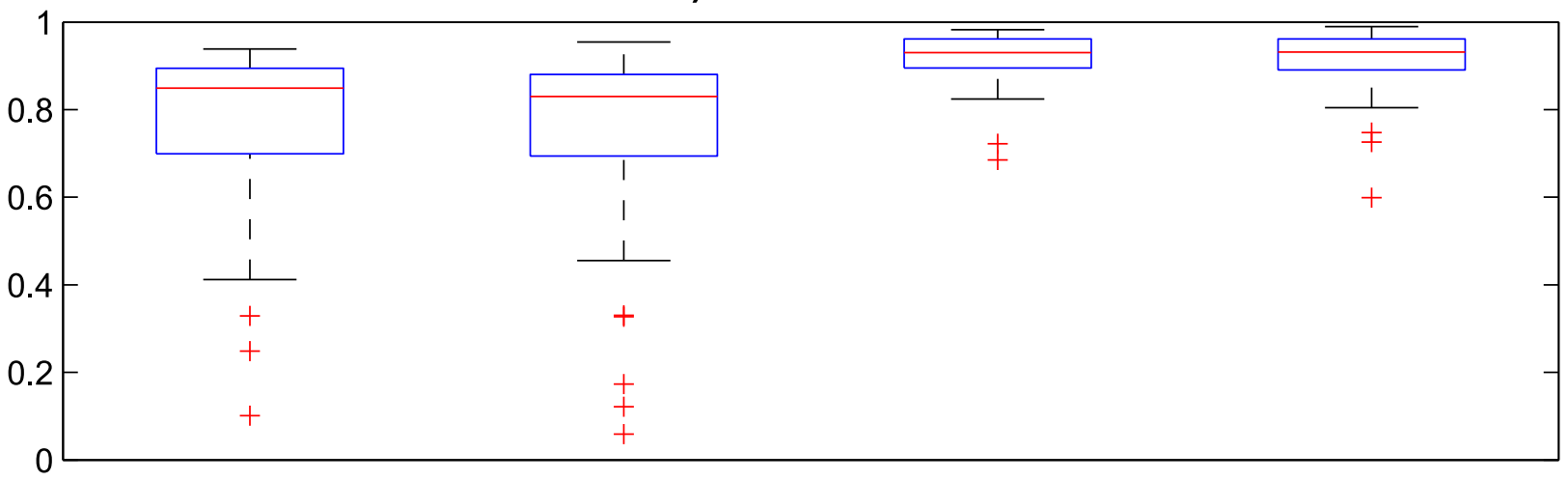

b) Root Mean Square Error

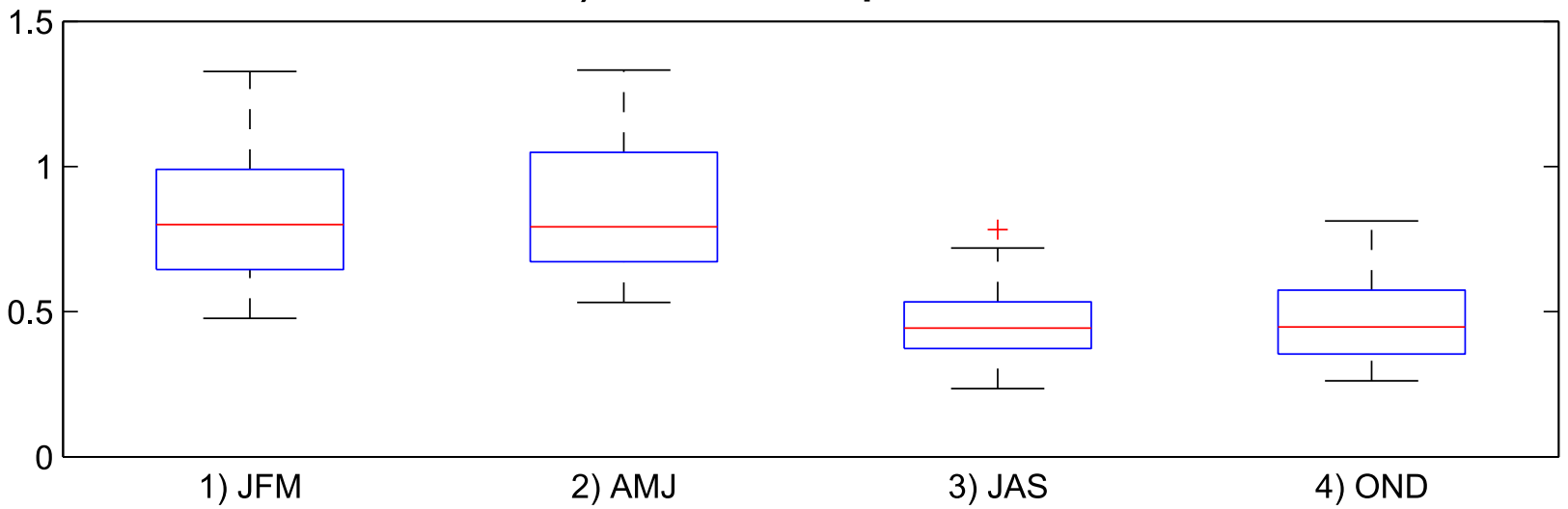

FIG. 3. As in Fig, 2, but computed from 35 members of the CESM1 and the $h(\mathbf{x})$ is computed for the seasonal mean, Northern Hemisphere SICE over 1920-2012; nonsignificant $h(\mathbf{x})$ is not set to 0 , no filtering is applied prior to regression, and $h(\mathbf{x})$ is computed for each month prior to the seasonal averaging: averaged 1) over JFM, 2) over AMJ, 3) over JAS, and 4) over OND.

the autumn (winter and spring) sea ice loss observed over the Chukchi Sea and Beaufort Sea (Okhotsk Sea) is not coherent with the long-term GW signal; that is, it does not satisfy simple pattern scaling. This is that part of the recent rapid sea ice decline that reflects both anthropogenic short-term forcing, internal variability, and nonlinearities. Note also that the winter and spring sea ice growth detected in the GW signal over the a) AMIP: Hurrell SST 1980-2010

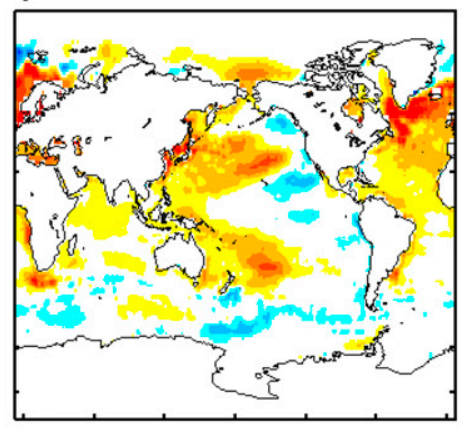

b) GW SST 1980-2010

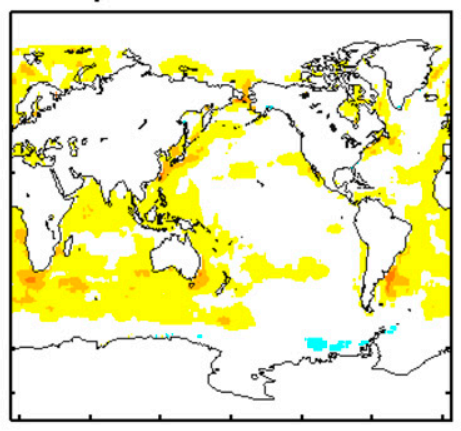

c) AMIP-GW

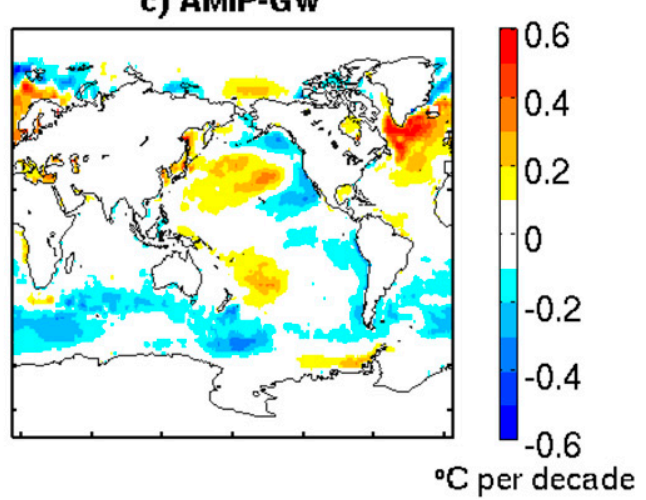

FIG. 4. Linear trends in annual-mean SST $\left({ }^{\circ} \mathrm{Cdecade}^{-1}\right.$ ) over 1980-2010 for (a) Hurrell (AMIP) SST, (b) GW SST, and (c) AMIP minus GW. 


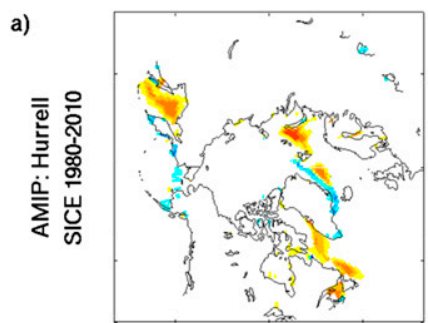

b)

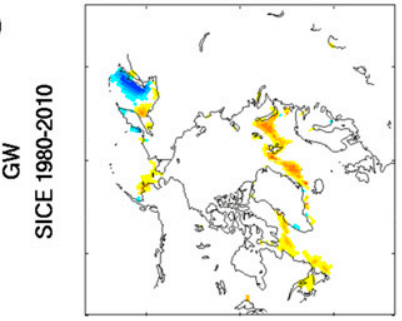

JFM
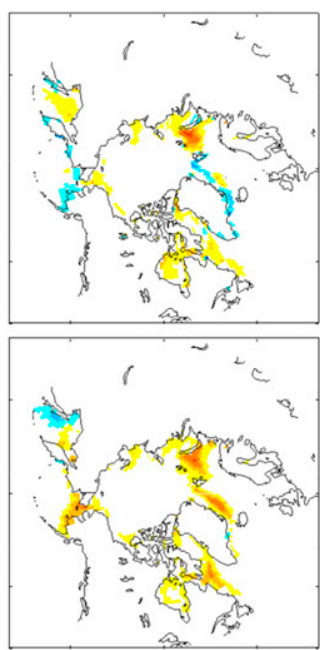

AMJ
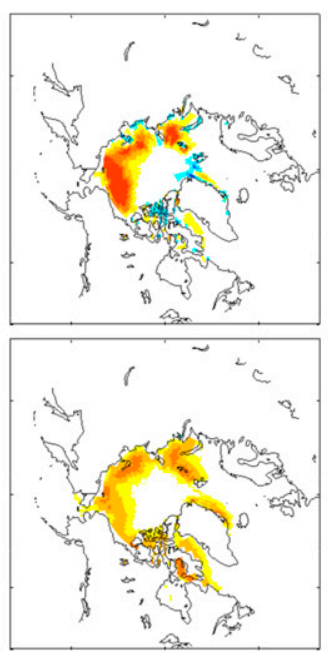

JAS
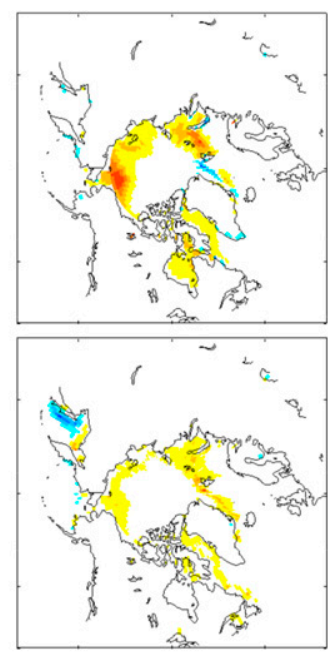

OND
$-18 \quad-14$
$-10$
$-6$
2
6
10
14
18
$\%$ per decade

FIG. 5. (left to right) Seasonal sea ice fraction trends $\left(\%\right.$ decade $\left.^{-1}\right)$ over 1980-2010 for (a) Hurrell (AMIP) SICE and (b) GW SICE.

Okhotsk Sea appears to be related to a spurious artifact in the Hurrell sea ice dataset that we are currently investigating. It is not consistent with the spatially and seasonally averaged SSTs in the region and likely does not represent a true global warming signal. Changes to estimates of sea ice over the preand postsatellite period will change the appearance of these patterns. It is unlikely that this issue will significantly affect the particular regional hydroclimate trends discussed here.

In the AMIP approach (as well as in two-tier dynamical seasonal forecasting), an ensemble of simulations forced with observed sea surface temperature and sea ice should satisfactorily capture continental climate signals if 1 ) these signals are controlled by signals in SSTs and/or sea ice, 2) the model is able to capture the physical processes involved, 3) the signals are statistically robust, and 4) the observed SST, sea ice, and continental data are accurate and representative. Acknowledging this, we focus on regions and seasons where the CAM5 AMIP ensemble is at least qualitatively consistent with $90 \%$ significant observed trends over the period 1980-2010 and where a simple measure of response signal strength within the ensemble is satisfied (section 3). While we will find several cases where these criteria appear to be satisfied, we acknowledge counterexamples in our survey; for example, our simulations do not reproduce recent statistically significant summer drying observed in California and European precipitation trends (not shown). While we cannot evaluate the various reasons why such mismatches occur within the scope of the paper, the intention here is to demonstrate the potential utility of our method of comparing the AMIP and GW signals, in anticipation of ongoing improvements in models and in observational data and improved understanding of the control of climatic signals by SSTs and sea ice.

\section{Results}

In the focus regions and seasons where AMIP results are consistent with statistically significant observed trends, we compare the AMIP and GW ensemble means, attributing their similarities to the pattern-scaled global warming response and their differences to the other sources of variability that need to be evaluated on a case-by-case basis.

\section{a. Northern Hemisphere surface temperature response}

Figure 6 shows the linear trends in January-March (Fig. 6a) and July-September (Fig. 6b) surface temperature (1980-2010) over the Northern Hemisphere (30$90^{\circ} \mathrm{N}$ ) for observations, for the AMIP ensemble mean, for the GW ensemble mean, and for AMIP minus GW. The gray shading highlights areas where the statistical significance of the trends, computed using the Student's $t$ test, is below $90 \%$. To illustrate the consistency of trends across each ensemble, the AMIP and GW ensemble means shown in Figs. 6-10 are reproduced in the supplemental material but with gray shading to highlight areas where the respective ensemble signal to noise, defined as the ensemble mean across each realization's trend divided by the ensemble standard 
a)

b)
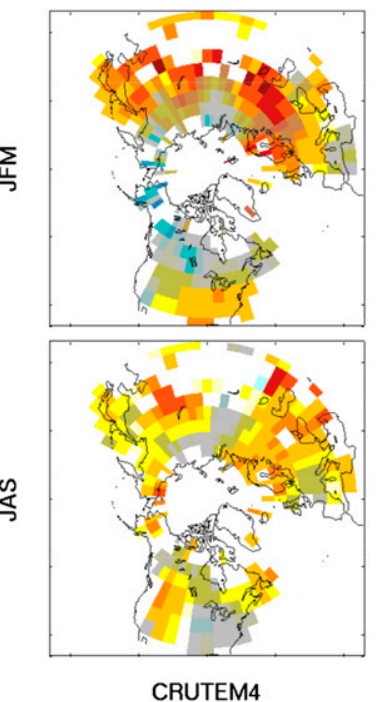

$-1.2$
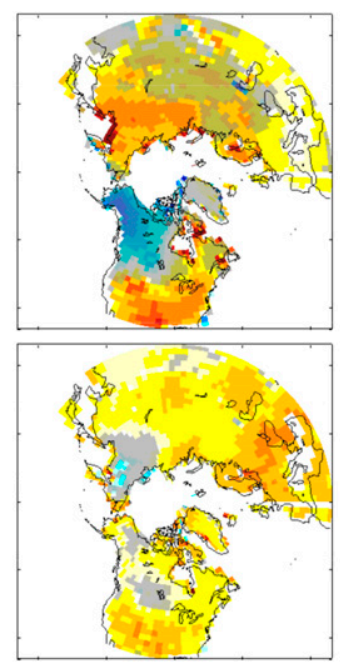

AMIP
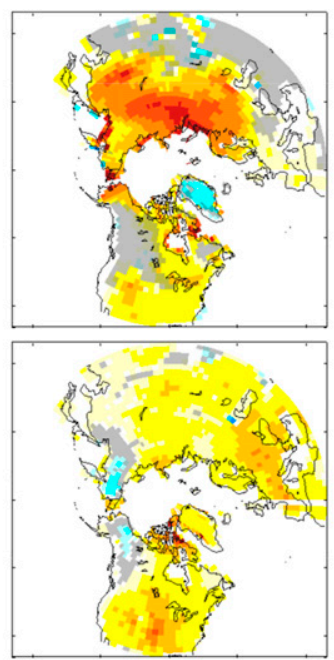

GW
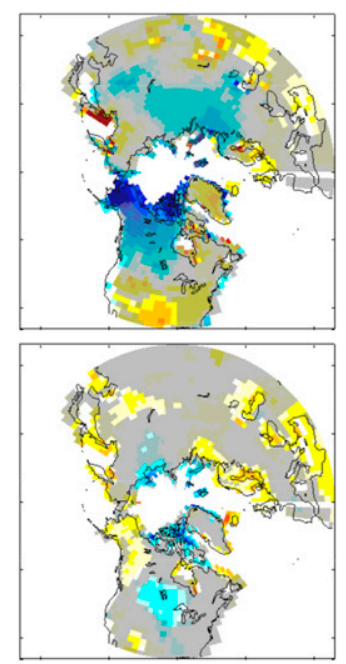

AMIP-GW

degrees ${ }^{\circ} \mathrm{C}$ per decade

FIG. 6. (a) JFM and (b) JAS Northern Hemisphere surface temperature trends ( ${ }^{\circ} \mathrm{C}$ decade ${ }^{-1}$ ) over 1980-2010 for (left)-(right) CRUTEM4, AMIP, GW, and AMIP minus GW. The gray shading is for regions where the statistical significance as described in the text is $<90 \%$.

deviation across each realization's trend, is less than one. According to Fig. 6, observed surface temperatures warm on average by $+0.5^{\circ} \mathrm{Cdecade}^{-1}$ over the entire Northern Hemisphere in both seasons. This is the case in all seasons (not shown). The warming reaches up to $+1.4^{\circ} \mathrm{Cdecade}^{-1}$ over Eurasia (Fig. 6a) in winter. Most of the observed trends are reproduced in the AMIP and the GW ensemble means. According to AMIP minus GW panels in the right-hand column in Fig. 6, the AMIP ensemble mean generally shows trends similar to the GW ensemble mean except in northwestern North America where it is colder by up to $2^{\circ} \mathrm{Cdecade}^{-1}$, which is consistent with the idea of a slowdown in this warming over the recent period (e.g., Dai et al. 2015). Finally, Fig. 6d shows that the GW ensemble mean only partially reproduces the warming simulated in autumn over the Chukchi Sea and the Beaufort Sea (AMIP trends are warmer than the observations by about $0.6^{\circ} \mathrm{C}$; not shown).

We conclude that most of the continental warming observed over the past 30 years in the Northern Hemisphere results from global warming, which in this framework is interpreted as forced by the continental response to greenhouse gas-driven oceanic warming. In winter, we find that winter cooling simulated in AMIP and to some extent observed over northwestern North America cannot be attributed to pattern-scaled global warming; Fig. 4 suggests, in agreement with previous studies (e.g., Mudryk et al. 2014), that the SST internal variability, in particular the decreasing phase of the PDO, plays a major role.

\section{b. Hydrological response}

\section{1) WINTER SNOW AT HIGH NORTHERN LATITUDES}

Figure 7 shows the trends in winter SWE over the high northern latitudes as observed in GlobSnow (Fig. 7a) and MERRA (Fig. 7b) and as simulated in the AMIP (Fig. 7c) and the GW (Fig. 7d) ensemble means. Figure 7e shows AMIP minus GW. According to Figs. 7a,b, both observations show SWE loss over northwestern Eurasia. However, while GlobSnow shows an increasing SWE trend over the eastern midlatitudes of North America and eastern Eurasia, MERRA shows a decreasing SWE trend in these regions. The AMIP ensemble mean (Fig. 7c) agrees qualitatively with both observations over northwestern Eurasia but only with GlobSnow over the eastern midlatitudes of North America. According to Figs. 7d,e, only the SWE loss observed over northwestern Eurasia is attributable to GW. On the other hand, the SWE increase observed over the eastern midlatitudes of North America in GlobSnow may stem from oceanic internal variability and/or anthropogenic forcing not related to global warming. This increasing SWE trend, seen only in the GlobSnow product, may also point to an error in the MERRA observational product or an issue with how SWE in this region is represented in the models.

Figure 8 is identical to Fig. 7 for SCF. According to Figs. 8a,b, both observations show an SCF decrease of up to $-10 \%$ decade $^{-1}$ along the Eurasian midlatitudes and an SCF increase along the western coast of North America. However, GlobSnow shows an SCF increase over central North America that is not seen in MERRA, 
a) GlobSnow

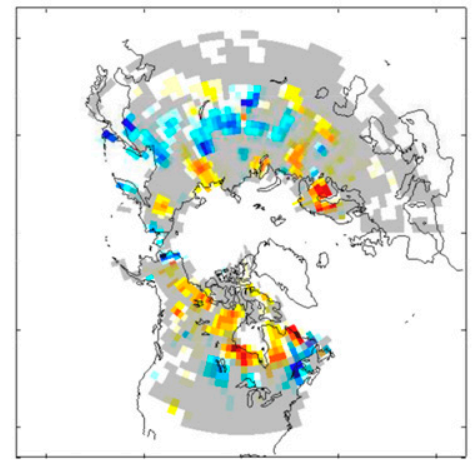

c) AMIP

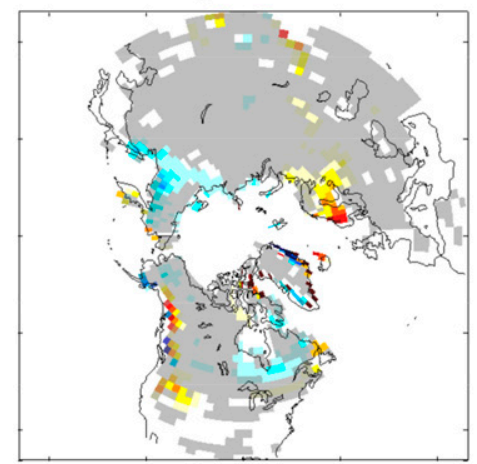

b) MERRA

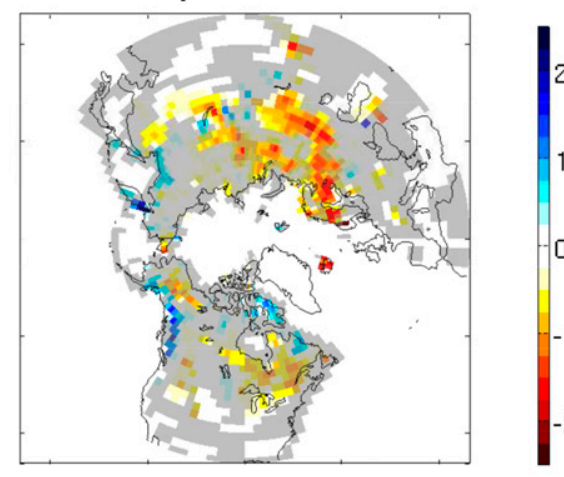

$\mathrm{cm}$ per decade

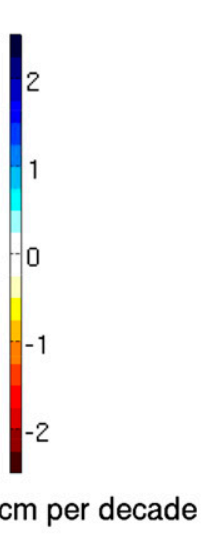

d) GW

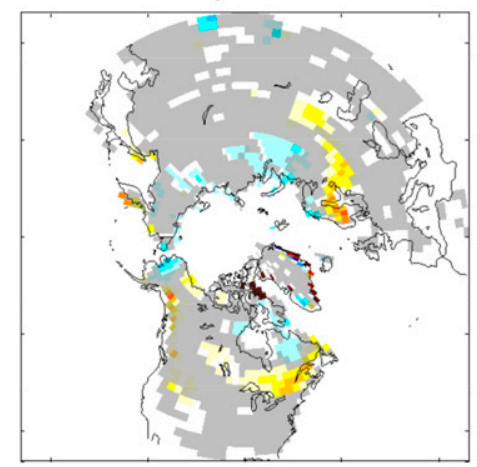

e) AMIP-GW

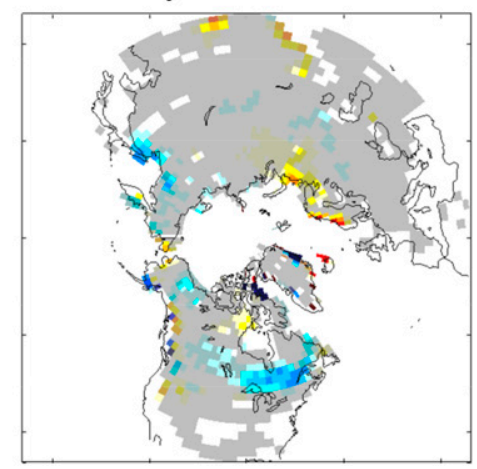

FIG. 7. JFM SWE trends (cm decade ${ }^{-1}$ ) over 1980-2010 for (a) GlobSnow, (b) MERRA, (c) AMIP, (d) GW, and (e) AMIP minus GW. The gray shading is for regions where the statistical significance as described in the text is $<90 \%$.

and MERRA shows a snow cover loss over North American midlatitudes that is not seen in GlobSnow. The AMIP ensemble mean (Fig. 8c) agrees qualitatively with both observations in northwestern Eurasia and to some extent over the Eurasian midlatitudes and the western coast of North America, but only with MERRA over the North American midlatitudes. An examination of Figs. 8d,e indicates that most of the snow cover loss observed over the midlatitudes (or in MERRA in the case of North America) are attributable to GW but not the SCF increase observed along the western coast of North America. We conclude that the winter SCF reduction observed over the past 30 years along the Eurasian and North American midlatitudes results from global warming but that the SCF increase observed along the western coast of North America results from remaining sources of ocean surface variability. Taken together, Figs. 4 and 8 are consistent with previous studies (e.g., Mudryk et al. 2014)—that SST internal variability, in particular the decreasing phase of the PDO, plays a major role in increasing the observed SCF over the western coast of North
America. Our results also highlight large differences in estimated trends from differing observational snow products.

\section{2) Winter PRECIPITATION IN NORTH AMERICA}

Figure 9 shows the trends in winter precipitation over North America (millimeters accumulated over the season per decade) as observed in CRU TS3.21 (Fig. 9a) and as simulated in the AMIP (Fig. 9b) and the GW (Fig. 9c) ensemble means. Figure 9d shows AMIP minus GW. According to Fig. 9a, observations show a precipitation decrease over the southern coast of Alaska, the southeastern coast of North America, and western North America and Mexico (up to $-50 \mathrm{~mm} \mathrm{decade}^{-1}$ in California and Florida) and a precipitation increase along the Appalachian Mountains and parts of British Columbia. According to Figs. 9b,c, most of the observed trends are reproduced in the AMIP ensemble mean but not in the GW ensemble mean. In agreement with previous studies (e.g., Hoerling et al. 2008; Deser et al. 2014), our estimated North American winter precipitation response to pattern-scaled global warming 


\section{a) GlobSnow}

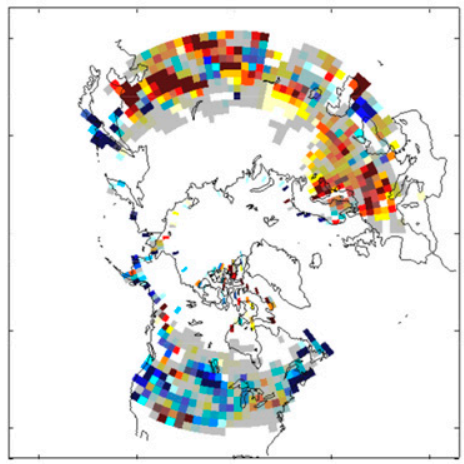

c) AMIP

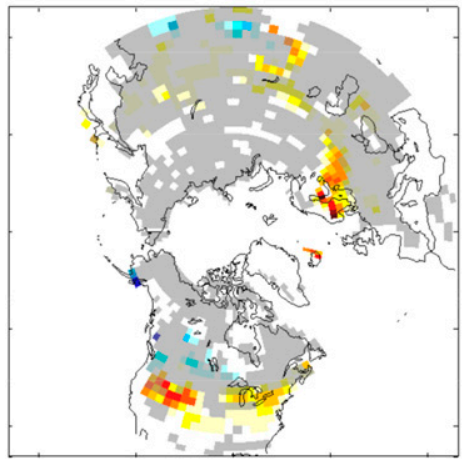

b) MERRA

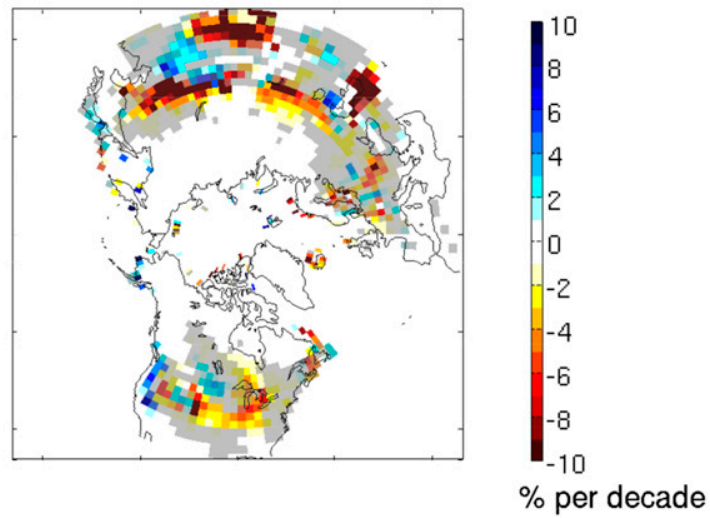

FIG. 8. As in Fig. 7, but for JFM SCF trends $\left(\%\right.$ decade $\left.^{-1}\right)$.

(Fig. 9c) shows a precipitation decrease over western Canada and an increase over Alaska. According to Fig. 9d, the precipitation pattern anomaly (AMIP minus GW) is very similar to the AMIP pattern (Fig. 9b).

We conclude that over the past $30 \mathrm{yr}$, almost none of the winter precipitation trends observed over North America can be attributed to pattern-scaled GW. Figure 4 suggests, in agreement with previous studies (e.g., McCabe et al. 2004), that the decreasing phase of the PDO, which could be internally generated or externally (Smith et al. 2016), plays a major role in driving the North American winter precipitation trends, thereby "hiding" the global warming signal. In addition, note that the increasing precipitation trend over the eastern midlatitudes of North America observed in CRU TS3.21 and simulated in the AMIP ensemble and in AMIP minus GW is consistent with snow cover trends discussed in section 3a and might be related to North Atlantic variability (Mudryk et al. 2014).

\section{3) Summer PRecipitation in Africa}

As a final illustration of the potential value of this approach, Fig. 10 shows the summer precipitation trends over Africa in the same format as Fig. 9. According to Fig. 10a, observations show a precipitation increase on average of $+40 \mathrm{~mm}^{\text {decade }}{ }^{-1}$ over the Sahel. According to Fig. 10b, most of this pattern is reproduced in the AMIP ensemble mean, albeit slightly shifted northward. In agreement with previous studies (Bader and Latif 2003; Hoerling et al. 2006), our estimated African summer precipitation response to global warming (Fig. 10c) shows a precipitation increase on average of $+20 \mathrm{~mm} \mathrm{decade}^{-1}$ over central and eastern Sahel (within $15^{\circ}-20^{\circ} \mathrm{N}$ ) and a precipitation decrease on average of $-20 \mathrm{~mm} \mathrm{decade}^{-1}$ over western Sahel and the Gulf of Guinea. According to Fig. 10d, the precipitation pattern difference is mostly positive (on average $+20 \mathrm{~m} \mathrm{decade}^{-1}$ ) over the western Sahel and the Gulf of Guinea, consistent with the GW driving reduced precipitation or relatively weak increases in precipitation compared to recent observed trends.

We argue here based on previous studies (e.g., Hoerling et al. 2006; Zhang and Delworth 2006; Ting et al. 2009, 2011) that SST variability associated with the increasing phase of the AMO, which could be internally generated or externally forced, is playing a major role in 
a) CRU

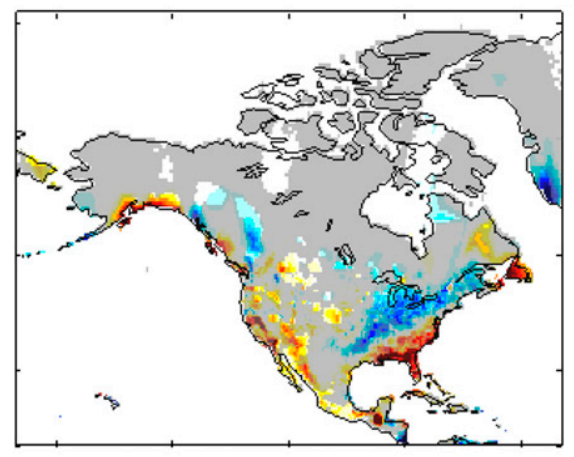

c) GW

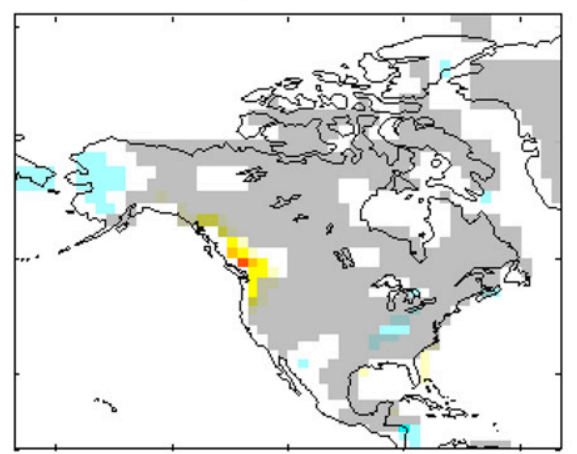

b) AMIP

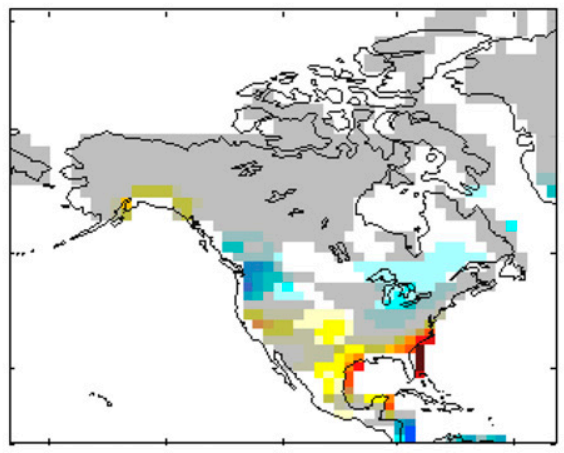

d) AMIP-GW

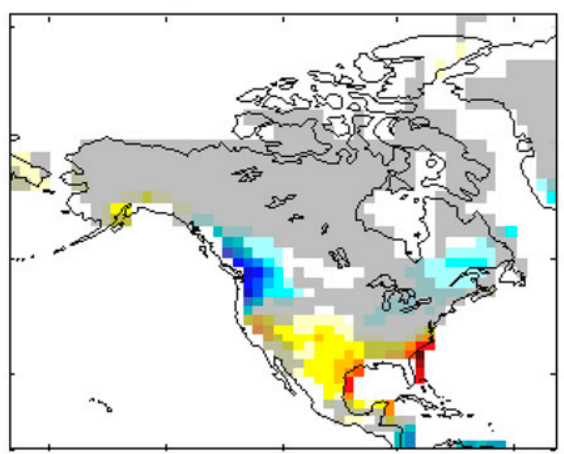

\section{$\begin{array}{llllllll}-50-40-30-20-10 \quad 0 & 10 & 20 & 30 & 40 & 50 & \text { per decade }\end{array}$}

FIG. 9. JFM land precipitation trends (mm decade ${ }^{-1}$; total precipitation over the season) over 1980-2010 for (a) CRU TS3.21, (b) AMIP, (c) GW, and (d) AMIP minus GW. The gray shading is for regions where the statistical significance as described in the text is $<90 \%$.

driving the African summer precipitation trends. The increasing phase of the AMO is associated with an SST increase to the north of the equator relative to the south, a northward-shifted ITCZ, and a summertime precipitation increase over the Sahel (e.g., Zhang and Delworth 2006; Ting et al. 2009; Caminade and Terray 2010; Ting et al. 2011). These same SST trend signatures are apparent in Fig. 4a, which shows a strong warming over the North Atlantic (on average $+0.3^{\circ} \mathrm{Cdecade}^{-1}$ ) that contrasts with a slight cooling (on average $-0.1^{\circ} \mathrm{Cdecade}^{-1}$ ) over the South Atlantic. The expected summer precipitation increase over the Sahel associated with these SST trends can be deduced in the observations shown in Fig. 10a and is directly simulated by our model as shown in Fig. 10b. The observed trends contrast with the previous 30 years (1950-80), when the strong summer drying observed over the Sahel (not shown) was associated with a strong cooling over the North Atlantic relative to the
South Atlantic and the decreasing AMO (e.g., Hoerling et al. 2006; Zhang and Delworth 2006; Ting et al. 2009, 2011).

Although our estimate of the summer precipitation response to global warming agrees with some previously published work (Bader and Latif 2003; Hoerling et al. 2006), it contrasts with others (e.g., Held et al. 2005; Lu and Delworth 2005; Biasutti and Giannini 2006; Caminade and Terray 2010; Mohino et al. 2011). These latter studies predict a precipitation decrease over the Sahel and increase over the Gulf of Guinea, which they associate with a global warming pattern of SSTs. According to previous studies (e.g., Bader and Latif 2003; Hoerling et al. 2006; Mohino et al. 2011), our estimate corresponds to a precipitation pattern usually associated with a warming in the Indian Ocean: the Indian Ocean warming increases subsidence over the western part of West Africa, thereby increasing precipitation over eastern Africa and decreasing it over western Africa. 
a) Observations

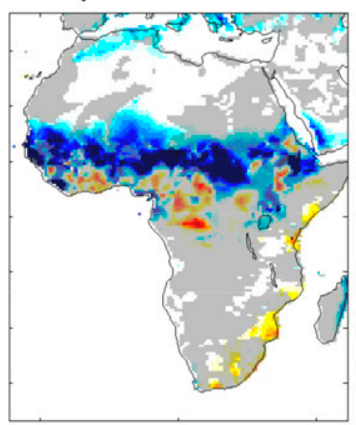

b) AMIP

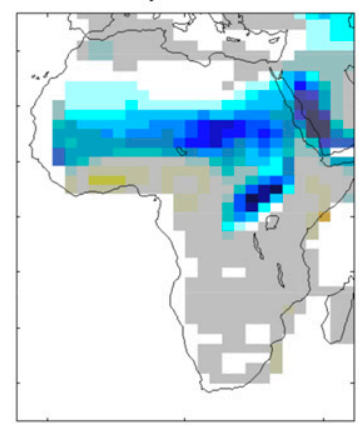

c) GW

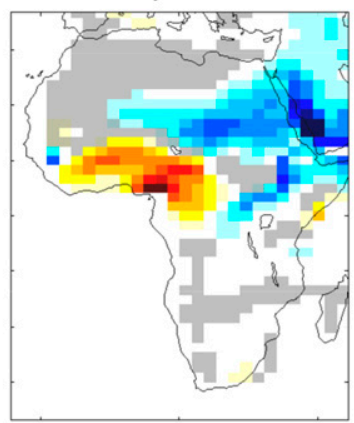

d) AMIP-GW

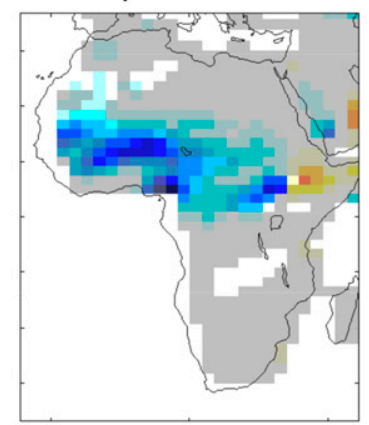

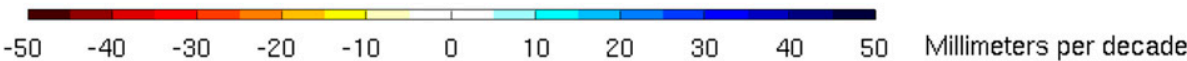

FIG. 10. As in Fig. 9, for JAS land precipitation trends ( $\mathrm{mm} \mathrm{decade}^{-1}$; total precipitation over the season).

The disagreement between our estimate of African summer precipitation response to global warming and other estimates may result from model differences. For example, our model may respond too strongly to Indian Ocean warming. Alternatively, this disagreement may result from differences between our observationally based estimate of the SST response to global warming and those derived from coupled ocean-atmosphere GCMs. For example, our GW estimate shows less warming in the tropical Pacific and tropical Atlantic (Fig. 4) as compared to the estimate in Figs. 2a,e from Mohino et al. (2011). A more complete decomposition of the response to regional SST changes is required to better explain these differences in the estimated GW signal.

\section{Discussion}

Our study uses a simple statistical method to estimate the global warming pattern of observed SST and SICE; this method has been updated for this study relative to Bichet et al. (2015). Using a large initial condition ensemble as a test bed for the updated method, we find that the estimation method is expected to capture more than $70 \%$ of the variance of the spatial pattern of $\mathrm{GW}$ in observed SSTs and between $70 \%$ and $90 \%$ in observed SICE depending on the season. Using the global warming pattern as an SST-SICE boundary condition in an AGCM simulation framework, we are able to attribute important aspects of observed continental trends to the pattern-scaled response to global warming $(\mathrm{GW})$. The continental climate trends associated with the GW driving include a Northern Hemisphere warming in all seasons, winter snow loss in northwestern Eurasia, and to some extent east African precipitation. In those regions where the AMIP simulations capture observed trends but the GW response is distinct, we gain insight into how GW might reinforce or oppose trends arising from other sources. Furthermore, our study highlights large differences across different observational snow products that require careful interpretation of regional hydroclimate trends related to snow cover. Note that despite using a very different methodology than the one used in Deser et al. (2016), both studies reach the conclusion that the internally generated component of winter SAT trends in North America is largely dynamically induced, whereas the forced component is primarily thermodynamically controlled (e.g., changes in SSTs). Whereas the approach used in Deser et al. (2016) is purely statistical and might suffer from potential biases in simulated SSTs and SICE, it presents the advantage of removing a very large sample of internal variability. On the other hand, our approach suffers from internal variability contamination but presents the advantage of being more dynamically oriented and uses observed patterns of SSTs.

With the two sets of prescribed SST-SICE simulations analyzed here, we are not in a position to directly diagnose continental trends not coherent with patternscaled GW. For example, we expect that the origin of trends in the AMO might involve a combination of short-term regional forcing from aerosol effects (e.g., Booth et al. 2012) and internal variability (e.g., Ting et al. 2009). Broadly, in this study we are not able to discriminate the many effects influencing ocean surface variability listed in the introduction apart from $\mathrm{GW}$, including short-term natural and anthropogenic forcings, nonlinearities, and so forth. To extend the study, it is therefore necessary to design additional experiments isolating these different factors. Extensions we are currently designing include separate sea ice loss and SST warming experiments, decomposition of the SST signal 
into separate regions (e.g., isolation of the Pacific or Atlantic Ocean), changes to radiative forcing, and repetition of these simulations with other AGCMs.

The results of this study are encouraging for its use in near-term decadal prediction. Following Hoerling et al. (2011), we extrapolate $g(t)$ into the future by making use of the projections from the CMIP5 archive. The more realistic pattern of warming would allow us, in regions and seasons where the prescribed SST-SICE model is evaluated to be reliable, to predict the regional-scale continental response to global warming. Additional experiments could be conceived to evaluate the impacts of internal variability, short-term aerosol forcing, ozone forcing, and so forth. Such experiments would also give insight into the timing of the emergence of the global warming signal from internal variability. One might ask, for example, when the impact of global warming dominates oceanic decadal internal variability and regional aerosol responses in African summer and North American winter precipitation trends. Here again, model uncertainty could also be estimated by carrying out these experiments with multiple AGCMs.

Acknowledgments. The authors thank the National Center for Atmospheric Research (NCAR) for providing access to the CAM5 code and access to the CCSM4 and CESM1 large ensemble data. Original simulations were carried out on the Compute Canada SciNet platform. This research has been supported by the Prévisibilité Climatique Décennale (PRECLIDE) Project, which was funded by the BNP Paribas Foundation and the Canadian Sea Ice and Snow Evolution (CanSISE) network.

\section{REFERENCES}

Bader, J., and M. Latif, 2003: The impact of decadal-scale Indian Ocean sea surface temperature anomalies on Sahelian rainfall and the North Atlantic Oscillation. Geophys. Res. Lett., 30, 2169, doi:10.1029/2003GL018426.

Biasutti, M., and A. Giannini, 2006: Robust Sahel drying in response to late 20th century forcings. Geophys. Res. Lett., 33, L11706, doi:10.1029/2006GL026067.

Bichet, A., M. Wild, D. Folini, and C. Schaer, 2011: Global precipitation response to changing forcing since 1870. Atmos. Chem. Phys., 11, 9961-9970, doi:10.5194/acp-11-9961-2011.

—, D. Folini, M. Wild, and C. Schaer, 2014: Enhanced central European summer precipitation in the late 19th century: A link to the tropics. Quart. J. Roy. Meteor. Soc., 140, 111-123, doi:10.1002/qj.2111.

— P. J. Kushner, L. Mudryk, L. Terray, and J. C. Fyfe, 2015: Estimating the anthropogenic sea surface temperature response using pattern scaling. J. Climate, 28, 3751-3763, doi:10.1175/JCLI-D-14-00604.1.

Booth, B. B., and Coauthors, 2012: Aerosols implicated as a prime driver of twentieth-century North Atlantic climate variability. Nature, 484, 228-232, doi:10.1038/nature10946.
Caminade, C., and L. Terray, 2010: Twentieth century Sahel rainfall variability as simulated by the ARPEGE AGCM, and future changes. Climate Dyn., 35, 75-94, doi:10.1007/ s00382-009-0545-4.

Compo, G. P., and P. D. Sardeshmukh, 2009: Oceanic influences on recent continental warming. Climate Dyn., 32, 333-342, doi:10.1007/s00382-008-0448-9.

Dai, A., 2013: The influence of the inter-decadal Pacific oscillation on US precipitation during 1923-2010. Climate Dyn., 41, 633646, doi:10.1007/s00382-012-1446-5.

_ J. C. Fyfe, S.-P. Xie, and X. Dai, 2015: Decadal modulation of global surface temperature by internal climate variability. Nat. Climate Change, 5, 555-559, doi:10.1038/nclimate2605.

Deser, C., and A. S. Phillips, 2009: Atmospheric circulation trends, 1950-2000: The relative roles of sea surface temperature forcing and direct atmospheric radiative forcing. J. Climate, 22, 396-413, doi:10.1175/2008JCLI2453.1.

,,-- M. A. Alexander, and B. V. Smoliak, 2014: Projecting North American climate over the next 50 years: Uncertainty due to internal variability. J. Climate, 27, 2271-2296, doi:10.1175/JCLI-D-13-00451.1.

- R. A. Tomas, and L. Sun, 2015: The role of oceanatmosphere coupling in the zonal-mean atmospheric response to arctic sea ice loss. J. Climate, 28, 2168-2186, doi:10.1175/JCLI-D-14-00325.1.

_ _ L. Terray, and A. S. Phillips, 2016: Forced and internal components of winter air temperature trends over North America during the past 50 years: Mechanisms and implications. J. Climate, 29, 22372258, doi:10.1175/JCLI-D-15-0304.1.

Fletcher, C. G., and P. Kushner, 2013: Linear interference and the northern annular mode response to tropical SST forcing: Sensitivity to model configuration. J. Geophys. Res. Atmos., 118, 4267-4279, doi:10.1002/jgrd.50385.

Gates, W. L., 1992: AMIP: The atmospheric model intercomparison project. Bull. Amer. Meteor. Soc., 73, 1962-1970, doi:10.1175/ 1520-0477(1992)073<1962:ATAMIP>2.0.CO;2.

Giannini, A., R. Saravanan, and P. Chang, 2003: Oceanic forcing of Sahel rainfall on interannual to interdecadal time scales. Science, 302, 1027-1030, doi:10.1126/science.1089357.

Harris, I., P. D. Jones, T. J. Osborn, and D. H. Lister, 2014: Updated high-resolution grids of monthly climatic observations. Int. J. Climatol., 34, 623-642, doi:10.1002/joc.3711.

Held, I. M., and Coauthors, 2005: Simulation of Sahel drought in the 20th and 21st centuries. Proc. Natl. Acad. Sci. USA, 102, 17 891-17 896, doi:10.1073/pnas.0509057102.

Hoerling, M., J. Hurrell, J. Eischeid, and A. Phillips, 2006: Detection and attribution of twentieth-century northern and southern African rainfall change. J. Climate, 19, 3989-4008, doi:10.1175/JCLI3842.1.

_ A. Kumar, J. Eischeid, and B. Jha, 2008: What is causing the variability in global mean land temperature? Geophys. Res. Lett., 35, L23712, doi:10.1029/2008GL035984.

_ , and Coauthors, 2011: On North American decadal climate for 2011-20. J. Climate, 24, 4519-4528, doi:10.1175/2011JCLI4137.1.

Hurrell, J. W., J. J. Hack, D. Shea, J. M. Caron, and J. Rosinski, 2008: A new sea surface temperature and sea ice boundary dataset for the Community Atmosphere Model. J. Climate, 21, 5145-5153, doi:10.1175/2008JCLI2292.1.

Jones, P. D., D. H. Lister, T. J. Osborn, C. Harpham, M. Salmon, and C. P. Morice, 2012: Hemispheric and large-scale land surface air temperature variations: An extensive revision and an update to 2010. J. Geophys. Res., 117, D05127, doi:10.1029/ 2011JD017139. 
Kay, J. E., and Coauthors, 2015: The Community Earth System Model (CESM) large ensemble project: A community resource for studying climate change in the presence of internal climate variability. Bull. Amer. Meteor. Soc., 96, 1333 1349, doi:10.1175/BAMS-D-13-00255.1.

Lau, N.-C., 1997: Interactions between global SST anomalies and the midlatitude atmospheric circulation. Bull. Amer. Meteor. Soc., 78, 21-33, doi:10.1175/1520-0477(1997)078<0021: IBGSAA $>2.0 . \mathrm{CO} ; 2$.

Lu, J., and T. L. Delworth, 2005: Oceanic forcing of the late 20th century Sahel drought. Geophys. Res. Lett., 32, L22706, doi:10.1029/2005GL022980.

— , G. Chen, and D. M. W. Frierson, 2008: Response of the zonal mean atmospheric circulation to $\mathrm{El}$ Niño versus global warming. J. Climate, 21, 5835-5851, doi:10.1175/ 2008JCLI2200.1.

McCabe, G., M. A. Palecki, and J. L. Betancourt, 2004: Pacific and Atlantic Ocean influences on multidecadal drought frequency in the United States. Proc. Natl. Acad. Sci. USA, 101, 41364141, doi:10.1073/pnas.0306738101.

Mohino, E., S. Janicot, and J. Bader, 2011: Sahel rainfall and decadal to multi-decadal sea surface temperature variability. Climate Dyn., 37, 419-440, doi:10.1007/s00382-010-0867-2.

Mudryk, L. R., P. J. Kushner, and C. Derksen, 2014: Interpreting observed Northern Hemisphere snow trends with large ensembles of climate simulations. Climate Dyn., 43, 345-359, doi:10.1007/s00382-013-1954-y.

— C. Derksen, P. J. Kushner, and R. Brown, 2015: Characterization of Northern Hemisphere snow water equivalent datasets, 1981-2010. J. Climate, 28, 8037-8051, doi:10.1175/ JCLI-D-15-0229.1.

Park, D.-S. R., S. Lee, and S. B. Feldstein, 2015: Attribution of the recent winter sea-ice decline over the Atlantic sector of the Arctic Ocean. J. Climate, 28, 4027-4033, doi:10.1175/ JCLI-D-15-0042.1.

Rienecker, M. M., and Coauthors, 2011: MERRA: NASA's Modern-Era Retrospective Analysis for Research and Applications. J. Climate, 24, 3624-3648, doi:10.1175/ JCLI-D-11-00015.1.

Santer, B. D., T. M. L. Wigley, M. E. Schlesinger, and J. F. B. Mitchell, 1990: Developing climate scenarios from equilibrium GCM results. Max Planck Institute for Meteorology Rep. 47, 29 pp.

Schubert, S. D., M. J. Suarez, P. J. Pegion, R. D. Koster, and J. T. Bacmeister, 2004: Causes of long-term drought in the U.S. Great Plains. J. Climate, 17, 485-503, doi:10.1175/ 1520-0442(2004)017<0485:COLDIT>2.0.CO;2.

Screen, J. A., and I. Simmonds, 2010: The central role of diminishing sea ice in recent arctic temperature amplification. $\mathrm{Na}$ ture, 464, 1334-1337, doi:10.1038/nature09051.
Seager, R., Y. Kushnir, C. Herweijer, N. Naik, and J. Velez, 2005: Modeling the tropical forcing of persistent droughts and pluvials over western North America: 1856-2000. J. Climate, 18, 4065-4091, doi:10.1175/JCLI3522.1.

Shin, S.-I., and P. D. Sardeshmukh, 2011: Critical influence of the pattern of tropical ocean warming on remote climate trends. Climate Dyn., 36, 1577-1591, doi:10.1007/ s00382-009-0732-3.

Smith, D. M., and Coauthors, 2016: Role of volcanic and anthropogenic aerosols in the recent global surface warming slowdown. Nat. Climate Change, 6, 936-940, doi:10.1038/ nclimate3058.

Solomon, A., and M. Newman, 2012: Reconciling disparate twentieth-century Indo-Pacific Ocean temperature trends in the instrumental record. Nat. Climate Change, 2, 691-699, doi:10.1038/nclimate1591.

Takala, M., K. Luojus, J. Pulliainen, C. Derksen, L. Lemmetyinen, J.-P. Karna, and J. Koskinen, 2011: Estimating Northern Hemisphere snow water equivalent for climate research through assimilation of space-borne radiometer data and ground-based measurements. Remote Sens. Environ., 115, 3517-3529, doi:10.1016/j.rse.2011.08.014.

Taylor, K. E., R. J. Stouffer, and G. A. Meehl, 2012: An overview of CMIP5 and the experiment design. Bull. Amer. Meteor. Soc., 93, 485-498, doi:10.1175/BAMS-D-11-00094.1.

Tebaldi, C., and J. M. Arblaster, 2014: Pattern scaling: Its strengths and limitations, and an update on the latest model simulations. Climatic Change, 122, 459-471, doi:10.1007/ s10584-013-1032-9.

Ting, M., Y. Kushnir, S. Richard, and C. Li, 2009: Forced and internal twentieth-century SST trends in the North Atlantic. J. Climate, 22, 1469-1481, doi:10.1175/2008JCLI2561.1.

, R. Seager, and C. Li, 2011: Robust features of Atlantic multi-decadal variability and its climate impacts. Geophys. Res. Lett., 38, L17705, doi:10.1029/2011GL048712.

Wang, H., and Coauthors, 2009: Attribution of the seasonality and regionality in climate trends over the United States during 1950-2000. J. Climate, 22, 2571-2590, doi:10.1175/ 2008JCLI2359.1.

Wu, L., and Coauthors, 2012: Enhanced warming over the global subtropical western boundary currents. Nat. Climate Change, 2, 161-166, doi:10.1038/nclimate1353.

Xie, S.-P., C. Deser, G. A. Vecchi, J. Ma, H. Teng, and A. T. Wittenberg, 2010: Global warming pattern formation: Sea surface temperature and rainfall. J. Climate, 23, 966-986, doi:10.1175/2009JCLI3329.1.

Zhang, R., and T. L. Delworth, 2006: Impact of Atlantic multidecadal oscillations on India/Sahel rainfall and Atlantic hurricanes. Geophys. Res. Lett., 33, L17712, doi:10.1029/ 2006 GL026267. 